\title{
Design of web systems for inventory control in the E-commerce sector under the Agile methodologies approach
}

\author{
Alexi Delgado $^{1}$, Enrique Lee Huamaní ${ }^{2}$, Simón Samaniego Diego ${ }^{2}$ \\ ${ }^{1}$ Mining Engineering Section, Pontificia Universidad Católica del Perú, Lima-Perú, kdelgadov@ pucp.edu.pe \\ ${ }^{2}$ Image Processing Research Laboratory, Universidad de Ciencias y Humanidades, Lima-Perú, ehuamaniu@uch.edu.pe
}

\begin{abstract}
Management control projects in a company have, in some cases, become a major conflict of order and decision making. In view of this, the present work seeks to achieve the design of an effective web system that provides the necessary tools to the company, through the Scrum methodology, which allows us to carry out projects of great complexity in a short time. In the case study, five Sprint were determined, which were based on stages of development of the application. The results of this study showed that the inventory control would help in the decision making of the sales made. The method applied to this study to carry out the design was very interesting to be able to propose to other companies.
\end{abstract}

Key words : Balsamiq, Laravel, Scrum,web prototype.

\section{INTRODUCTION}

It should be noted that the family dynamic, socially speaking, the time in the development of a software project oriented to the systems for inventory control can become extensive depending on the amount of requirements and changes caused by the new strategies of the management area or by the users themselves. For the work team the change with respect to the project objectives can be very difficult if an order in the activities is not managed and it can happen that the time of the work increases in an exponential way, therefore it is necessary the use of a flexible work methodology that can be adapted to the changes. Currently, we are focusing on the use of a new work method, which are the agile methodologies due to having a management and administration approach to project development [1], and also to be able to adapt to the big changes due to the constant communication with the work team.

This research will develop the design of an inventory control system in the e-commerce sector, the novelty of this work focuses on the design of a prototype of inventory control software based on the scrum methodology approach.. The reason for focusing on the area of inventory is because most small and medium enterprises today choose to maintain paper-based inventories which reflect a poor and unprofessional image [2] for their customers, and also get a disorganized report of purchases and inventory every time an employee performs a similar transaction [3]. Companies that decide to incorporate a web-based system are affected because some do not have the necessary security, nor do they provide reliable data; they also require continuous maintenance that does not guarantee an improvement in the process [4]. Therefore, when a customer buys a product, the employee must re-record his or her data and personal information, resulting in data redundancy leading to a long-term maintenance requirement [5].

To create the prototyping of a web system for inventory control, the Scrum methodology will be used due to its easy management and process control [6]. This work will involve 5 stages to obtain a better result, since this methodology allows us to carry out large projects in the short term [7]. The first stage shows the product portfolio, which includes 6 user stories. This stage was carried out with the client, to define what are the objectives of the system to be implemented [8]. Taking into account the stories, the second phase shows the Sprint Backlog, where the activities of the increments to be carried out are distributed [9]. In the third stage, the different meetings that will be held to develop the software are developed [10]. Stages 4 and 5 are responsible for developing the software and implementing new user stories.

The steps of the Agile Scrum methodology were followed in detail when developing the application of this paper. In the first Sprint, 6 user stories were collected, which are the main ones to create an optimal web system; the second stage chooses to delegate the activities that will be done to make the web system, taking into account the objectives to be performed, the third stage is Dayli Scrum [11], this is defined in which the client and the developers meet periodically to perform the details of implementation of the software to be developed [12]. The fourth and fifth stage consists in detailing the last steps of the design and implementing new user stories. The primary purpose is to design a web system for inventory control in e-commerce. With this system the process of inventory management will be streamlined by $60 \%$ and thus avoid the existing latencies when making the records in order to have a higher performance for the company to be organized and produce a greater number of sales and reports will also be made of sales completed per week to have better control.

In this paper, section II shows each of the steps of the methodology to implement, the increases of the most important processes of the company. Section III shows the delegated activities and in how much time the increments have to be done, together with the mockups of the interface designs to be implemented. Section IV shows the results and 
discussions derived from this research. Finally, section V shows the conclusions that have been submitted.

\section{METHODOLOGY}

In this section the details of the architecture of the SCRUM methodology together with the Balsamiq tool will be explained step by step in order to design web prototypes. The software will be developed in the language of php with the framework laravel accompanied by the database manager MySQL to make web services.

\subsection{Development technologies}

To carry out the design of the system interfaces, the Balsamiq prototyping software will be used. It makes the creation of the interfaces of the future web system much easier, due to the fact that it is a fast wireframing tool that benefits the user by providing an intelligent experience of drawing on a blackboard using a computer, allowing the models to be made much easier [13]. To develop the web system we will use the Mysql database administrator, which is open source and works with relational data, this means that it uses multiple tables that are interconnected between them, in order to store all types of data and organize them correctly [14], php will be used as the programming language due to being open source and will help in the web development of the system along with HTML, which is a language used to generate dynamic web pages. As a tool to facilitate work, we will use Laravel, which is a framework that reuses components with the PHP framework. This framework is very popular for its content and its solidity; follows the MVC model, that design is considered Model-View-Controller. It will also improve the speed of user credentials to be created on the web system [15].

\subsection{Incremental model}

At this stage we will describe which the most important processes are and which their goals to realize the future web system are. This requires delivering increments at intervals; the increments will be divided as follows: The first increase to be considered will be the management of clients, followed by the control of products, finally, in the third process the control of sales must be considered. In Figure 1, the sequence of processes using the incremental model.

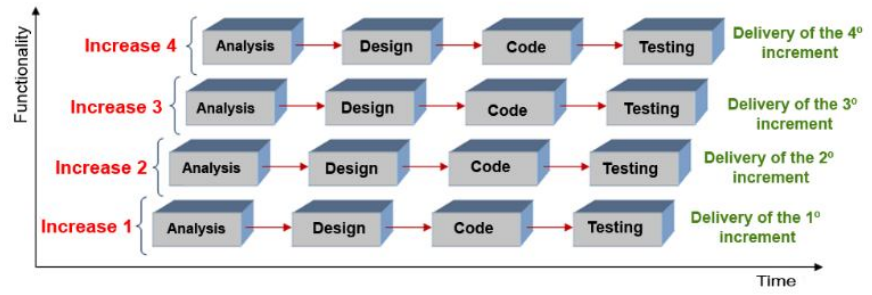

Figure 1: Incremental model of the web system for inventory control

\subsection{Physical Structure Design}

In this increment, there will be a complete record of all the clients that frequent the system, therefore, there will be a complete database of each one of the users. In the second increment, a product control will be performed in order to recognize how many we have at the disposition of the client, which products are out of stock; and thus, recognize the demand that each product has for a future purchase of supplies and/or manufacture of products. In the third increment, a report will be made on how many sales were completed daily, which allows the current status of the company to be recognized, along with its income.

\subsection{Scrum}

This methodology is regularly applied to a large set of good practices to work in an equitable and equal way, collaborating with each other, to finally get the best result from the web system for inventory control of an e-commerce [16].

\section{A. Product Backlog}

In this first stage, the most important requirements for the company will be gathered, this will be done together with the client so that the client gives us the information in detail about which are the guidelines to carry out the system and thus achieve its proposed objective.

\section{B. Sprint Backlog}

At this stage, the Master Scum is identified, who is the leader of the Scrum team, he delegates the tasks to the team, so each one is responsible for making the assignments in a certain time, for this, the Trello tool will be used, obtaining a better organization.

\section{Daily Scrum}

The meetings will be held every two weeks so that the developers get more time to make the determined increases, these meetings will be given to finalize details of the software and implement new innovations.

\section{Sprint Review}

As any project, in the last stage there are always new implementations to be made, so, in the current stage, the client will be able to implement new user stories for the improvement of the web system.

\section{E. Sprint Retrospective}

Finally, in this section the improvements requested by the client will be made and the last details for the system will be given. In Figure 2, the increments that will be made for the development of the web system are shown.

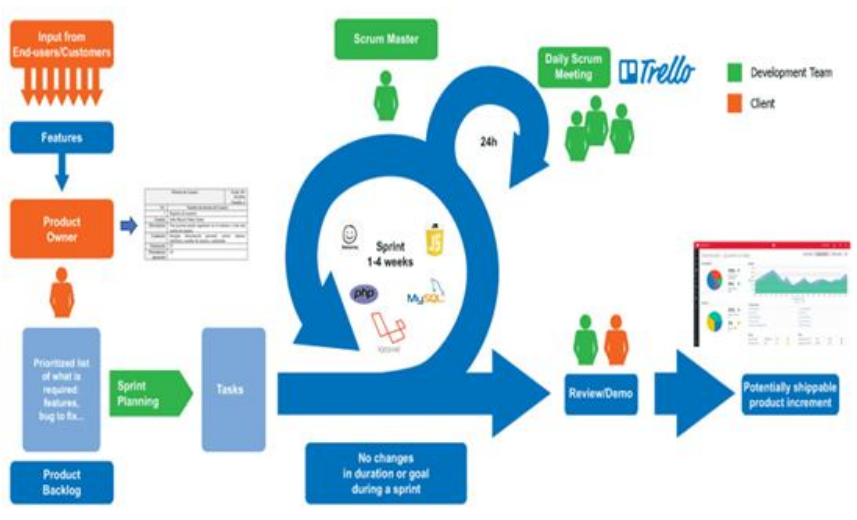

Figure 2:Scrum model applied to a web system for e-commerce inventory control 


\section{CASE STUDY}

\subsection{Product Backlog}

The client, who in this case would be the manager of the company, has requested a web system to have control of the inventories, for this we need to have a list of all the user stories that will be collected together with the client to know what the objectives of this web system will be. In Table 1, you can see the requirements to develop the web system, which were made in conjunction with the client.

Table 1: User stories of the web system for inventory control in e-commerce

\begin{tabular}{|c|l|}
\hline $\mathbf{N}^{\circ}$ & \multicolumn{1}{|c|}{ User Stories } \\
\hline 1 & $\begin{array}{l}\text { As an employee I need to perform customer registration } \\
\text { to have a better overview of their data. }\end{array}$ \\
\hline 2 & $\begin{array}{l}\text { As an administrator I need to register the products to } \\
\text { make a weekly report of the most sold product as a } \\
\text { result of the daily sales. }\end{array}$ \\
\hline 3 & $\begin{array}{l}\text { As an employee I need to register the sale to keep a } \\
\text { better control of the quantities sold during the week. }\end{array}$ \\
\hline 4 & $\begin{array}{l}\text { As an employee I need to track the type of payment that } \\
\text { is made to make an accounting report. }\end{array}$ \\
\hline 5 & $\begin{array}{l}\text { As an administrator I need to be able to print the weekly } \\
\text { report of the total sales to have a better control of the } \\
\text { company if needed. }\end{array}$ \\
\hline
\end{tabular}

Within the first stage, System use cases are considered, these serve to specify the behavior of the web system through the interaction between the system and the user.

Table 2 shows the user stories collected, all of them belong to a process that we will call System Use Case, to develop the web system design.

Table 2:System Use Case

\begin{tabular}{|c|c|c|}
\hline $\mathbf{N}^{\circ}$ & User Stories & Use Case \\
\hline 1 & $\begin{array}{l}\text { As an employee I need to perform } \\
\text { customer registration to have a better } \\
\text { overview of their data. }\end{array}$ & $\begin{array}{c}\text { Manageme } \\
\text { nt of } \\
\text { Clients }\end{array}$ \\
\hline 2 & $\begin{array}{l}\text { As an administrator I need to register the } \\
\text { products to make a weekly report of the } \\
\text { most sold product as a result of the daily } \\
\text { sales. }\end{array}$ & $\begin{array}{l}\text { Products } \\
\text { Control }\end{array}$ \\
\hline 3 & $\begin{array}{l}\text { As an employee I need to register the } \\
\text { sale to keep a better control of the } \\
\text { quantities sold during the week. }\end{array}$ & \multirow{3}{*}{$\begin{array}{c}\text { Sales } \\
\text { Control }\end{array}$} \\
\hline 4 & $\begin{array}{l}\text { As an employee I need to track the type } \\
\text { of payment that is made to make an } \\
\text { accounting report. }\end{array}$ & \\
\hline 5 & $\begin{array}{l}\text { As an administrator I need to be able to } \\
\text { print the weekly report of the total sales } \\
\text { to have a better control of the company if } \\
\text { needed. }\end{array}$ & \\
\hline
\end{tabular}

\subsection{Sprint Backlog}

The Sprint are the modules that we will use, each of them was developed with the MVC Pattern. In addition, each module has different models; therefore, in this stage the connection with the database was made, achieving the creation of the interfaces accordingly.

- Sprint I Management of Clients: We implemented the registration of the client along with his personal information considering if a delivery is desired; also, this enables a database of past clients allowing a future contact and a continuous transaction with them.

- Sprint II Product Control: In order to inform the seller about the stock of the products, a product register was implemented to know the public demand, and a more aware continuous purchase of the input or product.

- Sprint III Sales Control: A login will be developed for the registration of the employee, the client and the product, this interface was developed with the language PHP and JavaScript because both languages work in an efficient way.

\subsection{Daily Scrum}

In this third stage, weekly meetings were held so that the client and the software developer could maintain contact and discuss the relevant requirements in order to acquire the best performance of the web system. With Trello tool, it was considered that the process will be more organized and complete, as shown in Figure 3.

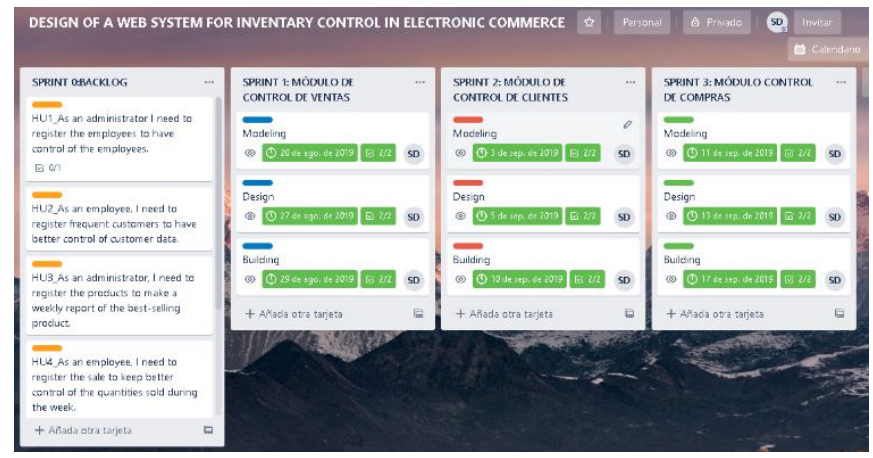

Figure 3: Trello tool applied to the design of a web system for the control of e-commerce inventories.

\subsection{Spring Review}

At this stage, it is necessary to point out that the client was able to modify the results by creating new user stories. So the final results are shown below. In Figure 4, all the data and attributes of the products are shown in order to carry out the reports. 


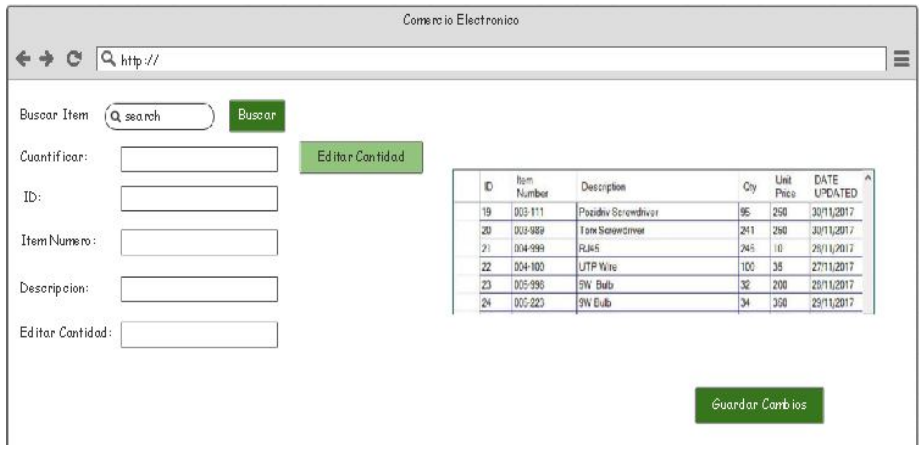

Figure 1: Inventory Control

At this stage, Raspbian, which is the OS of Raspberry, will be used. The necessary packages (sensors) will be installed for the software to operate and perform programming based on the requirements.

\subsection{Spring Retrospective}

In this last stage new interfaces were designed in which the new inventory records were implemented, during this stage it was possible to implement the new requirements for a better development of the software.

\section{RESULTS AND DISCUSSION}

As indicated in the introduction section, the novelty of this research was the use of agile methodology for the development of inventory software, since traditional methodologies could not adapt to changes. As an expected result, it has been proven that this method of work can help reduce activity time. Analyzing this information we can see that the agile methodologies fulfill their role well when changes occur, unlike the traditional methodology that when changes occur the number of day's increases considerably, but it is very good when there are no changes in the development. There are different methodologies but Scrum proved to be beneficial through several installations, since it allowed for on-time delivery, proper communication within the team, and allowed for the best quality to perform the work in agreement with the company manager and overcome the problems that occurred in the course of the design since it is a highly flexible methodology. However, it is argued that although it could have been beneficial, this would not have been the case if it had been a large-scale job [17].

\section{CONCLUSION}

In particular of the case study, the web system worked effectively in conducting purchases and sales of the company's products and safeguarded the personal data of customers, effectively performing the reports and statistics of sales that were made in a given time.

The methodology used was Scrum, with which it was possible to define the time needed for each Sprint or activity to be resolved for the completion of the project. Likewise, the flexibility of the methodology allowed to implement or correct the attributes of the design to obtain a more optimal result.
This work can contribute by serving as a model for new research work with reference to the realization of web systems of transactions and stock of items. In addition, new attributes can be implemented to the present like, for example, to have a better control of the inventories by means of their mobiles, creating mobile applications with the IONIC platform; for the direct application of the companies that consider to need to improve their sales systems For future studies it is recommended to take into consideration how many kilos of food or liters of water the dispenser can hold, with the aim of having a constant refill that benefits the health of the pets. On the other hand, although the case study of this research was to focus on a food dispenser, it is reiterated that Raspberry Pi has proven to be a flexible tool; therefore, it is considered capable of contributing to social problems such as problems in education, economy, etc.

\section{REFERENCES}

[1] A. Delgado and H.Flor,"Selection of the best air purifier system to urban houses using AHP," 2017 CHILEAN Conference on Electrical, Electronics Engineering, Information and Communication Technologies, CHILECON 2017 - Proceedings2017-January, pp. 1-4, 2017.

[2] "Gestión del sistema de inventarios orientado a pequeñas y medianas empresas, PYMEs, ecuatorianas del sector ferretero: caso de estudio," Rev. Espac., no. 2018, 2020.

[3] T. A. Vityazeva and A. A. Mikheev, «Information Loss in Measurement Signal Filtering Systems», in 2019 8th Mediterranean Conference on Embedded Computing, MECO 2019 - Proceedings, 2019. https://doi.org/10.1109/MECO.2019.8759995

[4] A. Ahmad, N. U. Khan, and A. W. Abbas, «PHP+MySQL based online examination system with power failure handling and dropbox capability», in Proceedings - 7th International Conference on Software Security and Reliability Companion, SERE-C 2013, 2013, pp. 21-25. https://doi.org/10.1109/SERE-C.2013.27

[5] Y. Shikunov, Y. Stepchenkov, D. Khilko, and D. Shikunov, «Data redundancy problems in data-flow computing and solutions implemented on the recurrent architecture», in Proceedings of the 2017 IEEE Russia Section Young Researchers in Electrical and Electronic Engineering Conference, ElConRus 2017, 2017, pp. 335-338. https://doi.org/10.1109/EIConRus.2017.7910559

[6] A. Srivastava, S. Bhardwaj, and S. Saraswat, «SCRUM model for agile methodology», in Proceeding - IEEE International Conference on Computing, Communication and Automation, ICCCA 2017, 2017, vol. 2017-January, pp. 864-869. https://doi.org/10.1109/CCAA.2017.8229928

[7] L. Benedicenti et al., «Applying scrum to the army: A case study», in Proceedings - International Conference on Software Engineering, 2016, pp. 725-727. https://dl.acm.org/doi/10.1145/2889160.2892652

[8] H. S. Sverrisdottir, H. T. Ingason, and H. I. Jonasson, The Role of the Product Owner in Scrum-comparison between Theory and Practices», Procedia - Soc. Behav. 
Sci., vol. 119, pp. 257-267, mar. 2014.

https://doi.org/10.1016/j.sbspro.2014.03.030

[9] R. T. Hans, «Work in Progress - The Impact of the Student Scrum Master on Quality and Delivery Time on Students' Projects», in Proceedings - 5th International Conference on Learning and Teaching in Computing and Engineering, LaTiCE 2017, 2017, pp. 87-90. https://doi.org/10.1109/LaTiCE.2017.22

[10] B. L. Romano and A. D. Da Silva, «Project management using the scrum agile method: A case study within a small enterprise», in Proceedings - 12th International Conference on Information Technology: New Generations, ITNG 2015, 2015, pp. 774-776. https://doi.org/10.1109/ITNG.2015.139

[11] A. Delgado and I. Romero, "Applying the Grey Systems Theory to Assess Social Impact from an Energy Project," Proceedings of the 2018 IEEE 25th International Conference on Electronics, Electrical Engineering and Computing, INTERCON 2018, 8526372, 2018.

[12]D. Pauly, B. Michalik, and D. Basten, «Do daily scrums have to take place each day? A case study of customized scrum principles at an E-commerce company», in Proceedings of the Annual Hawaii International Conference on System Sciences, 2015, vol. 2015-March, pp. 5074-5083. https://doi.org/10.1109/HICSS.2015.601
[13] Balsamiq Mockups Descargar (2019 Última versión) para Windows 10, 8, 7». [Online]. Available in: https://www.filehorse.com/es/descargar-balsamiq-mock ups/. [Acceded: 26-dec-2019].

[14] L. Zhang, H. Y. Ning, and Y. Yang, «A new type MySQL integrated mutual authentication security model», in Proceedings - 2016 6th International Conference on Instrumentation and Measurement, Computer, Communication and Control, IMCCC 2016, 2016, pp. 253-257. https://doi.org/10.1109/IMCCC.2016.14

[15] M. Sendiang, S. Kasenda, A. Polii, and Y. R. Putung, «Optimizing Laravel Authentication Process», in Proceedings - 2018 International Conference on Applied Science and Technology, iCAST 2018, 2018, pp. 247-251. https://doi.org/10.1109/iCAST1.2018.8751257

[16] A. Delgado, P. Montellanos and J. Llave, "Air quality level assessment in Lima city using the grey clustering method," IEEE ICA-ACCA 2018 - IEEE International Conference on Automation/23rd Congress of the Chilean Association of Automatic Control: Towards an Industry 4.0 - Proceedings8609699, 2019.

[17] Ifra and J. K. Bajwa, "Analysis of Scrum metrics in Indian SME's», in Proceedings - 2016 International Conference on Micro-Electronics and Telecommunication Engineering, ICMETE 2016, 2016, pp. 667-670. https://doi.org/10.1109/ICMETE.2016.125 